\title{
Modos de Ler Livros em Meios Digitais: Transformações da Experiência
}

\author{
Luciana Dadico \\ Universidade de São Paulo, SP, Brasil.
}

\begin{abstract}
Resumo: Este artigo apresenta uma pesquisa empírica cujo objetivo foi descobrir como leitores leem livros na tela digital. Uma teoria da experiência constituída no âmbito da chamada "escola de Frankfurt" contribuiu para o desenho do método que balizou este estudo. Foram entrevistados individualmente quatro leitores adultos, residentes no estado de São Paulo, de forma semiaberta, gravada e sem uso de questionário. Estas entrevistas produziram imagens dos objetos em foco na pesquisa, a partir das quais investigou-se a apercepção de tais objetos e as relações estabelecidas com eles pelos leitores. Os modos como os leitores liam livros na tela foram destacados e articulados às categorias imanentes do livro em tela, permitindo individuar padrões que participam da experiência de leitura. Emergiram como modos de ler livros em tela a leitura flutuante, a leitura frenética a leitura eficiente, ancoradas em elementos específicos da obra e empreendidas por um leitor utilitarista e receoso de aventurar-se em experiências novas. Considera-se que as tendências de leitura apontadas participam de e na estruturação de novas formas da experiência, bem como da formação cultural do indivíduo na era digital.
\end{abstract}

Palavras-chave: Leitura, Livros-texto, Novas Mídias, Experiência, Teoria Crítica.

\section{Ways of Reading Books in Digital Media: Transformations of Experience}

\begin{abstract}
This paper presents an empirical research whose aim was to discover how readers read books on the digital screen. A theory of experience built under the so-called "Frankfurt school" framework contributed to design the method that shaped this study. Four Brazilian adult readers were individually interviewed with a semi-structured method (recorded and using no questionnaire). These interviews produced images of the objects focused in the research, from which it was possible to investigate the apperception of such objects and the relationships that the readers established with them. Ways in which the readers read books on the screen were highlighted and articulated to the immanent categories of books on the screen, allowing the individualization of patterns that participate in the reading experience. The floating reading, the frenetic reading and the efficient reading emerged as ways of reading books on the screen. In such ways, the reading activity is anchored in specific elements of the literary work, undertaken by a pragmatic and fearful reader, who is afraid to launch himself through new experiences. We consider that these reading trends take part in the new structures of experience, as well as in the cultural education of the individual in the Digital Era.
\end{abstract}

Keywords: Reading, Books, New Media, Experience, Critical Theory. 


\title{
Modos de Leer Libros en Medios Digitales: Transformaciones de la Experiencia
}

\begin{abstract}
Resumen: En este artículo se presenta una investigación empírica dirigida a averiguar cómo los lectores leen libros en la pantalla digital. Una teoría de la experiencia elaborada en el contexto de la "Escuela de Frankfurt" contribuyó al diseño del método que dio forma a este estudio. Cuatro lectores adultos, que residen en el estado de Sao Paulo, fueron entrevistados individualmente de forma semiabierta, grabada y sin uso de cuestionario. Estas entrevistas produjeron imágenes de los objetos de la investigación, de las cuales se investigaron la apercepción de tales objetos y las relaciones establecidas con ellos por los lectores. Las formas en que los lectores leen libros en la pantalla fueron resaltadas y articuladas a las categorías inmanentes del libro en la pantalla, lo que permitió individualizar las estandarizaciones que participan en la experiencia de lectura. La lectura flotante, la lectura frenética y la lectura eficiente surgieron como formas de leer los libros en pantalla, ancladas en elementos específicos de la obra literaria, llevadas a cabo por un lector utilitarista y temeroso de aventurarse en nuevas experiencias. Se considera que las tendencias de lectura identificadas participan de y en la estructuración de nuevas formas de experiencia, y también de la formación cultural del individuo en la Era Digital.
\end{abstract}

Palabras clave: Lectura, Libros, Nuevos Medios, Experiencia, Teoría Crítica.

\section{Introdução}

Este artigo traz à discussão os resultados de uma pesquisa empírica realizada com o intuito de investigar a leitura de livros digitalmente mediada. O objetivo primeiro do estudo era descobrir como leitores brasileiros leem livros em uma tela digital. A investigação partiu da hipótese que a mediação digital afeta a experiência de ler, a despeito de se considerar a literatura uma arte alográfica.

Dados recentes (Instituto Pró-Livro, 2016) oferecem algumas pistas sobre o contexto no qual esta investigação se insere. Os tipos de materiais mais lidos entre nós são os jornais e as revistas; o livro mantém-se em terceiro lugar, respondendo por $42 \%$ destas leituras. A maioria dos brasileiros lê privadamente, em casa ( $81 \%$ ), em detrimento das bibliotecas, escolas e outros espaços públicos. Os brasileiros ainda leem mais livros em papel, embora a proporção no uso de suportes digitais esteja crescendo, alcançando cerca de $15 \%$ dos leitores em trânsito (no ônibus, avião, metrô etc.) e $6 \%$ daqueles que leem em casa. Enquanto 73\% dos brasileiros preferem ver TV no seu tempo livre (número ligeiramente em queda), cresce a proporção daqueles que realizam atividades diversas em meio digital, como navegar na Internet (47\%), assistir a filmes e vídeos em casa (44\%), usar aplicativos de comunicação (43\%), escrever (40\%), usar redes sociais (35\%) e ler jornais ou revistas (24\%). A Internet vem sendo mais utilizada também para aquisição de livros, por meio de compra (15\%), downloads (4\%) ou compartilhamento de arquivos digitais. Já utilizaram a rede alguma vez $67 \%$ dos brasileiros (eram $54 \%$ em 2011), e $63 \%$ fazem uso frequente dela. Embora o uso mais frequente da Internet seja para comunicação interpessoal (66\%), é grande também a participação em redes sociais, fóruns, blogs e o acesso a produtos culturais diversos, como música, vídeos, filmes e TV (50\%), além de jogos (34\%) e compras (27\%). Ler livros, em papel ou digital, é a atividade escolhida por $24 \%$ dos brasileiros para despender seu tempo livre. $15 \%$ utilizam a Internet para ler livros; $13 \%$ para buscar informações sobre livros e $8 \%$, para escrever seus próprios textos. $34 \%$ do total de leitores já leu livros digitais. A distribuição etária para a leitura de livros online é relativamente homogênea, de $19 \%$ na faixa entre 11 e 13 anos e $21 \%$ entre 18 e 24 anos, com queda mais acentuada depois dos 70 anos (7\%). Os suportes mais utilizados para esta leitura são os celulares e smartphones (56\%), seguidos dos computadores (49\%), tablets e iPads (18\%) e leitores digitais (4\%).

Tais dados mostram que não apenas o uso da Internet vem crescendo significativamente no Brasil, mas que muitas atividades associadas ao uso da rede, como é o caso da leitura de livros, vêm sendo também ampliadas. E que os meios digitais não são utilizados com uma única finalidade. Embora as atividades de 
comunicação e produtos audiovisuais estejam na dianteira dentre suas preferências de uso, a proporção de leitores de livros que vêm migrando do suporte em papel para os suportes digitais não para de crescer: $34 \%$ não é um número inexpressivo, principalmente em uma comparação retroativa. A pesquisa também mostra que a leitura em suporte digital, ao contrário do que se supunha, não é atividade restrita aos mais jovens, embora a proporção de seu uso entre os idosos seja menor. Outro dado que chama a atenção é o fato de que os leitores digitais voltados exclusivamente para a leitura de livros vêm sendo largamente superados pelos aparelhos multiplataforma, em particular por aqueles mais portáteis, como é o caso dos celulares e smartphones, a despeito da aparência mais distante destes em relação àquela do livro tradicional em papel. Vale destacar que estes resultados contradizem muitas crenças e estereótipos alimentados em relação ao uso dos meios digitais para a leitura de livros. A necessidade de compreendermos melhor este universo, tendo em conta a importância da leitura de livros para a formação do indivíduo, faz-se premente.

A pesquisa empírica relatada neste artigo teve como objetivos específicos descrever as características do livro na tela digital (as quais serão sucintamente apresentadas), bem como a experiência de leitura digitalmente mediada - este o argumento principal do texto que se segue. Após a conclusão de sua primeira fase inicial, foi possível compreender de que maneira a mediação digital afeta a aparência do livro em seus aspectos temporais e espaciais, e constatar que esta aparência é substancialmente distinta daquela do livro tradicional em papel, descrita em estudos anteriores (Dadico, 2012). Partindo deste ponto, tornava-se natural supor que a experiência de leitura circunscrita pelo novo objeto mediador seria também diversa. A segunda etapa da pesquisa, aqui abordada, foi então estruturada de modo a oferecer uma descrição das experiências dos leitores de livros em tela, a qual nos permite compreender melhor as novas formas de ler, ao mesmo tempo em que esclarece as diferenças entre estas novas modalidades de leitura e aquelas mediadas por livros tradicionais.

Espera-se que este artigo contribua, de forma direta, para melhorar os conhecimentos disponíveis sobre a leitura, o livro e a mediação da experiência, e também para a compreensão dos fenômenos culturais em curso na era digital. Espera-se, outrossim, que este trabalho possa agregar-se aos estudos críticos sobre mediação e ao conjunto de pesquisas empíricas realizadas sob inspiração da Teoria Crítica da Sociedade. Em sentido mais amplo, acredito que este artigo seja de interesse de psicólogos e educadores às voltas com questões relacionadas à leitura.

\section{Métodos}

Foram entrevistados ao longo da pesquisa dez leitores adultos, brasileiros e residentes no estado de São Paulo. Todos possuíam nível superior de formação. As entrevistas foram realizadas individualmente, de forma semiaberta, sem a aplicação de questionário e registradas em um gravador digital. Aconteceram entre janeiro de 2014 e junho de 2015, em uma sala silenciosa reservada para esse fim e tiveram duração de 45 a 120 minutos. Nos primeiros encontros, os leitores discorreram sobre temas como a leitura, os livros e os meios digitais. Destes dez leitores, quatro dispuseram-se a participar da segunda etapa da investigação, que envolveu a escolha e a leitura de um livro em meio digital. Foram agendadas então segundas entrevistas, para que os leitores pudessem contar como ocorreram suas leituras no intervalo entre nossos dois encontros. Os resultados aqui apresentados concentram-se na análise destas quatro últimas entrevistas. Os verdadeiros nomes dos leitores serão substituídos no texto por nomes arbitrários, a fim de preservar o sigilo de suas identidades.

Tanto Laís (36 anos) quanto Tereza (32 anos) trabalhavam em ou para diferentes editoras de livros, com funções variadas. Na época da pesquisa, Laís estava envolvida com o desenvolvimento de uma área de livros digitais em sua editora, coletando dados sobre público, técnicas e ferramentas digitais. Tereza trabalhava em um arquivo de imagens digitais, buscando informações sobre elas (especialmente dados autorais) e organizando sua catalogação. Amanda (29 anos) trabalhava em um órgão governamental de apoio a empresas, oferecendo consultoria em ciência e tecnologia. Todas as três ofereceram-se para participar do estudo a partir de um anúncio veiculado por uma agência universitária de notícias. Sérgio (42 anos) foi indicado por um terceiro pesquisador e trabalhava como professor universitário. Os suportes para leitura empregados por eles, respectivamente, foram um notebook, um tablet, um aparelho celular e um e-reader da marca Kobo. Quanto aos gêneros escolhidos para leitura: Laís optou por ler uma coletânea de histórias fantásticas; Tereza, um livro espírita; Amanda, um livro de fantasia em inglês; e Sérgio, um livro de crítica musical. 
Durante os encontros, os leitores puderam discorrer livremente sobre os livros que tinham lido. Às vezes, eram feitas perguntas para esclarecer algum ponto específico, ou estimulá-los a refletir acerca de determinado assunto. As gravações não foram transcritas, em razão das diferentes formas de análise que tocam à fala e ao texto escrito. $\mathrm{O}$ material gravado foi ouvido repetidas vezes durante o processo de análise. Por meio destas escutas, foi possível identificar algumas das imagens construídas e descritas pelos leitores acerca dos objetos em foco na pesquisa - o livro em tela e seus diversos elementos - e como os leitores se relacionavam com estes. A partir daí, tornou-se possível compreender como os leitores leram os livros escolhidos. Esta escuta continuada das entrevistas possibilitou investigar como se articulavam, na experiência de cada leitor, elementos que influenciavam sua leitura, a saber: a) a si próprio como leitor (formação, rol de interesses); b) objeto mediador; c) obra literária; d) modos de ler, em seus aspectos temporais (ritmo, duração, frequência), espaciais (locais, ocasião) e contingenciais (qualidade da leitura, funções e como esta atendia a necessidades específicas do sujeito).

A atenção às imagens descritas nas entrevistas tinha por objetivo preservar na análise das falas seu caráter expressivo, como unidade forma-conteúdo, em sua própria linguagem. A partir da descrição destas imagens, buscou-se estabelecer redes de relações entre os elementos que elas descreviam, com vistas à busca de diferenças e aspectos comuns às descrições dos leitores. As inter-relações destacadas durante o processo de análise foram elencadas em três grupos: 1) o "leitor" e "livro digital"; 2) o "leitor" e a "obra"; e 3) o "leitor" e o "como" de sua leitura. Os padrões ou estereotipias na atividade do leitor capazes de interferir de algum modo na experiência de leitura foram então agrupados e descritos mantidas as ressalvas acerca do caráter não invariante, mas histórico e culturalmente fundado desta análise, ressaltando-se $\mathrm{o}$ aspecto qualitativo deste trabalho.

Antes das entrevistas, os leitores foram informados sobre as questões éticas envolvidas no estudo, tais como riscos implicados, direito à desistência e sigilo - tópicos incluídos na leitura do Termo de Consentimento Livre e Esclarecido assinado pelos participantes. A coleta de dados desta pesquisa iniciou-se após o cadastramento do projeto de pesquisa na Plataforma Brasil, sob número CAAE 10156813.0.0000.5561, e a obtenção de parecer consubstanciado favorável, número 389.239, emitido pela CEPH-IP em 09/09/2013.

\section{A leitura de livros como experiência}

Antes de expor os resultados empíricos da pesquisa realizada, tratamos brevemente dos critérios empregados para avaliar as transformações nos modos de ler dos leitores, que envolvem discutir a possibilidade de se caracterizar a atividade de leitura como experiência.

O conceito de experiência em Psicologia usualmente envolve a suposição de que aquilo que o sujeito aprende ou já aprendeu em sua história de vida exerce alguma influência na realização de uma atividade presente. Não raro a palavra é empregada como sinônimo mesmo de aprendizado. Do ponto de vista epistemológico, por sua vez, a experiência apresenta-se um passo necessário no processo de construção do conhecimento que nasce da percepção sensível e da interpretação de dados empíricos (em contraste com a análise lógica e a especulação filosófica). Tomadas em conjunto, estas concepções dizem respeito ao indivíduo, à sua capacidade de conhecer e educar-se. Este sentido individualizante ou individualizado da palavra "experiência" será problematizado por pensadores como Walter Benjamin e Theodor Adorno. Sem ignorar as múltiplas conotações recebidas pelo termo e criticando-as em sua raiz, estes autores defendem a ideia de que a experiência é coletivamente estruturada. Quer dizer, longe de ser imediata ou natural, passível de descrições estritamente biológicas, a experiência não é o resultado causal de certas circunstâncias ambientais e respectivo agrupamento de variáveis, mas uma construção histórica, mediada, multideterminada, simultaneamente individual e coletiva.

Benjamin foi um dos primeiros a investigar as condições históricas e culturais da experiência, e é justamente em meio a seus estudos sobre literatura que nasce uma das mais conhecidas teorias sobre o assunto. Valendo-se da psicanálise, mas também da obra de outros filósofos e escritores, Benjamin (2015) sugere que o modo como nossa memória se constitui, incluindo a maneira como percebemos, conservamos as imagens e as expressamos em linguagem, está relacionado às condições materiais da existência. Condições estas que mudam radicalmente na modernidade, desde quando desponta como protótipo o homem das grandes cidades, isolado, adaptado ao trabalho mecanizado e exposto a um sem fim de estímulos perceptivos. Isso significa dizer que aquilo que a "experiência" do morador dos campos e períodos anteriores - expressa pela capacidade do orador 
de narrar e de contar histórias - perdeu seu lugar. O homem moderno lê e escreve, mas não sabe narrar. O saber que o velho acumulou ao longo de sua vida não interessa mais ao jovem, que vive em um mundo continuamente transformado e precisa estar sempre pronto para o novo. A ascensão do livro impresso e do romance, especialmente no contexto da Revolução Industrial (com o advento das máquinas rotativas e dos jornais), colabora para a dissolução da experiência, acirrando a separação entre indivíduo e comunidade. E, no entanto, a literatura comporta um elemento social fundante, sem o qual ela não se realiza como arte. O leitor precisa colocar a experiência em campo para reconstruir o universo da obra e realizá-la esteticamente, alimentando-se de um tempo outro, encerrado na obra, mas projetado para o futuro por meio do exercício criador da leitura.

É necessário ressaltar que, em virtude do caráter coletivo da experiência, as potencialidades abertas pela leitura estão articuladas a elementos que não são de domínio exclusivo do indivíduo, e não dependem, portanto, unicamente do esforço ou capacidade individuais. Importa então conhecer melhor as contingências que cercam a leitura hoje, naquilo que elas oferecem como possibilidade ou limite para que a experiência de leitura. No ensaio "Teoria da semiformação", Theodor Adorno (2010) elucida de que modo o declínio da experiência está relacionado à crise do projeto de formação cultural do indivíduo burguês, atacado em seu ideal de autodeterminação desde que a cultura, reificada, foi transformada em valor. De onde o alerta para que também nós não incorramos no erro de reificar a leitura como experiência, designando-a como ideal a ser atingido. A reificação da experiência e da cultura solapa o processo de construção do conhecimento, fazendo com que esquemas alheios ao indivíduo se the interponham a partir do exterior, como arremedos da experiência autônoma do sujeito frente ao objeto. O que não significa, por outro lado, ignorar as reflexões e saberes historicamente construídos em nome de uma experiência supostamente ingênua. Nesse campo, seria falacioso vender um repouso conciliador, tal como prometido por tantas propostas pedagógicas e reformas educacionais. O que se espera é que o leitor seja capaz de realizar uma análise imanente da obra literária (mesmo que opte por não fazê-lo). Lembrando, mais uma vez, que não se trata de estipular modelos para a leitura, priorizando técnicas de um investigador da literatura em detrimento daquilo que é "ondulante e móvel na apre- ciação literária" (Cândido, 1999, grifos do autor), capaz de desvelar seu sentido humano e beleza, para além dos dogmas. É a liberdade de espírito embutida em uma leitura e crítica impressionista, como nos lembra Cândido, quem reserva à literatura seu caráter civilizador.

A rigor, a crítica imanente seria acessível a qualquer leitor, em sua capacidade de compreender, descrever e explicar uma obra literária de forma integrada, alcançando seu(s) eventual(is) conteúdo(s) de verdade (Adorno, 2009). Isto implica, contudo, perceber a obra como unidade estrutural, na qual forma e conteúdo são elementos indissociáveis. Que uma leitura crítica acabe se tornando prerrogativa mais ou menos restrita a determinados tipos sociais e grupos de especialistas é um problema a ser denunciado, que ameaça a autonomia do sujeito, e decorre da indesejável reificação da experiência literária. Daí a importância de se assegurar ao leitor comum a possibilidade de realização de uma experiência estética como fruto de sua própria leitura - critério que funda a presente investigação. Grosso modo, isto significa um contato pessoal com a obra, alheio a padrões exteriores estipulados por um professor ou crítico, por exemplo. A experiência de ler faz-se meio $e$ fim da atividade de leitura, sem antepor-se a esta, permitindo ao leitor transcender a obra literária e realizá-la como uma (nova) experiência. Partindo desta ideia, torna-se possível compreender melhor o que está em jogo em meio às transformações da leitura, do livro e da cultura que estão em curso. Em sentido contrário a um estudo positivo dos fenômenos envolvidos na mediação, pode-se dizer que os meios digitais mesmo despontam em função de aspectos da estrutura de experiência que tornam possíveis as novas formas de recepção e difusão dos textos na era digital.

\section{As categorias do livro em tela}

Para que se possa compreender melhor a análise dos resultados apresentados neste artigo, convém recuperar rapidamente os resultados da primeira etapa deste estudo, que revelou como características do livro em tela a:

a) efemeridade; b) bidimensionalidade; c) disposição em rede; d) luminosidade; e) supervisibilidade; f) alta-portabilidade; g) inconstância do fundo; h) responsibilidade; i) inflexibilidade; j) multifuncionalidade; k) personificação; l) conservação temporária; m) acessibilidade imediata; e n) semipadronização. 
A efemeridade (a) diz respeito à "aparição" do objeto condicionada à alimentação elétrica do dispositivo digital, sem a qual o livro permanece invisível para o leitor. A bidimensionalidade (b) refere-se à mudança no aspecto tridimensional do livro tradicional, que, independentemente do tamanho do dispositivo de suporte, agora encerra-se na tela plana. A inconstância do fundo $(\mathrm{g})$ corresponde às alterações de padrão da página. Se antes o texto fixava-se ao papel e as páginas eram giradas, agora é a tela (o fundo) quem se mantém constante, enquanto o texto é rolado, mormente de cima para baixo, e seguido pelos olhos. Enquanto o cinema era responsável por promover uma ilusão de movimento a partir de fotografias em sequência, agora promove-se uma ilusão de materialidade, sensorialmente provocada, uma vez que os pixels reunidos de forma organizada e próxima ao sujeito parecem dispor-lhe um objeto e não uma imagem, apenas. A inconstância também se relaciona com a luminosidade (d) da tela e o tipo de luz emitida pelos dispositivos digitais, a qual, por outro lado, contribui também para atrair os olhos do leitor e manter o campo fenomenológico instaurado entre o leitor e o dispositivo. A disposição em rede (c) refere-se às conexões internas ou externas ao livro que passam a organizar a relação entre o leitor e o objeto. A inflexibilidade (i) do livro em tela expressa a ilusão de que certos arquivos, software ou hardware, e relação entre eles, podem ser modificados segundo a vontade do usuário comum. A responsibilidade (h) descreve a forma como a simultaneidade na transmissão e recepção dos dados digitais favorece, ou mesmo compele, os usuários a interagirem com o dispositivo, esteja ele ou não conectado à Internet. A alta-portabilidade (f), bem exemplificada pelo fato de que dificilmente alguém se separa de seu aparelho celular nos dias de hoje, associa-se ao armazenamento digital da obra em forma de dados. A multifuncionalidade (j) dos dispositivos digitais aponta para a possibilidade de utilização dos dispositivos digitais para um grande conjunto de tarefas. Como tendência, a multifuncionalidade pode explicar a pequena adesão do conjunto de leitores brasileiros aos e-readers desenhados exclusivamente para a leitura do livro. A personificação (k) refere-se ao fato de que, ao tornar-se meio para um grande conjunto de tarefas no cotidiano do usuário, o dispositivo digital acaba fortemente pessoalizado. A acessibilidade imediata $(\mathrm{m})$ denota a possibilidade permanente de acesso aos conteúdos disponíveis em rede a partir de qualquer aparelho conectado à Internet, independentemente do (arquivo do) livro estar fisicamente sob a posse do leitor. A conservação temporária (l), por outro lado, é uma característica que mostra a redução no tempo de conservação do livro, ora dependente de um conjunto de fatores que dificultam a garantia permanente de acesso à obra. A semipadronização (n), por fim, mantém-se como categoria do livro digitalmente mediado, desde que a linguagem escrita faculta ao leitor estabelecer ritmo de leitura próprio, embora as demais categorias do livro em tela tendam a promover uma leitura cada vez mais tipificada, conforme apontado a seguir.

\section{A apercepção dos objetos envolvidos na leitura}

Relações do leitor com o livro em tela

Em virtude de suas características, o livro em tela parece favorecer certos modos de leitura. A maneira como se dá esta articulação entre livro em tela e leitura, empreendida pelos leitores em sua experiência, precisa ser analisada em detalhe.

A efemeridade e a luminosidade da tela, como categorias do livro, poderiam nos fazer supor que o leitor teria mais facilidade para manter-se atento ao texto, e que tal atenção exigiria também um uso mais intensivo de sua memória. Se a luz azul da tela (Cajochen et al., 2011) ajuda o leitor a manter-se mais desperto (note-se que nenhum dos leitores relatou sentir sono ao ler, como acontecia com o livro em papel), tornando sua leitura também mais veloz, a pesquisa mostrou que nem por isso o leitor mostra-se concentrado na obra como unidade integrada - o que contribuiria para melhorar a lembrança daquilo que leu. Além disso, a combinação entre efemeridade e conservação temporária, que poderia impelir o leitor a uma relação mais intensiva como texto, acaba contrabalançada pela acessibilidade imediata das informações, pois o acesso rápido à obra sob a forma de dados é facilitado pela mídia digital e pela Internet. A memorização da obra substitui-se à memória de sua localização como dado. Isto compromete a capacidade do leitor de apreender e memorizar o material lido: os leitores exibem pouca precisão em seus relatos, esquecendo-se de nomes e fazendo poucas referências críticas à obra ou a passagens dos textos lidos (resultados coerentes com estudos de Mangen, Walgermos, \& Brønnick, 2013 e de Noyes \& Garland, 2014). 
Em outras palavras: o compromisso do leitor com a memorização do texto lido se reduz, enquanto sua preocupação com as estratégias de busca de informações aumenta. A localização do livro em meio aos próprios arquivos era uma preocupação relativamente frequente entre os leitores. Uma das leitoras entrevistadas demonstrava irritação com o fato de esquecer-se que já possuía um título, repetindo desnecessariamente a atividade de busca e aquisição de um mesmo livro sempre que precisava dele. Operações abstratas, não apenas de busca do livro em si, mas das próprias linhas nas páginas e pontos de retomada que permitem ao leitor seguir com sua leitura e torná-la fluída, tornam-se necessárias em virtude da mediação do software e da bidimensionalidade da tela. Indicadores numéricos substituem-se então à apercepção intuitiva, acrescentando tarefas novas à atividade de ler. Se estas tarefas não parecem constituir uma dificuldade para leitores familiarizados com o uso de dispositivos digitais para leitura, como é o caso de Sérgio e Amanda, o mesmo não se dá com as leitoras que migraram há pouco para os novos suportes, como é o caso de Tereza e Laís. Tereza enfrentava dificuldades com a mudança de páginas, por exemplo, o que perturbava a continuidade da leitura.

A distração ao ler, que se tornou uma questão educacional candente em nossos dias, também se modifica no livro em tela. A alta-portabilidade concorre para a dispersão, ao promover a leitura do livro em qualquer lugar. Lembrando que a portabilidade também é atributo do livro tradicional, embora este seja tendencialmente mais pesado que a maioria dos dispositivos digitais de leitura (com a vantagem de poder ser utilizado mesmo onde não haja energia elétrica ou acesso à rede). Por outro lado, a luminosidade e a supervisibilidade da tela atraem o leitor para o campo fenomenal do dispositivo, reduzindo a perturbação dos estímulos ambientais e fazendo com que a atenção do leitor à tela cresça. Essa atenção, no entanto, não é necessariamente dedicada ao livro e à leitura, uma vez que a multifuncionalidade do dispositivo digital oferece, internamente, um conjunto bastante variado de atividades concorrentes. Este fato desdobra-se, por um lado, em uma redução da atividade leitora por parte do usuário do dispositivo digital - que tende a executar tarefas mais afins à mediação digital (como a comunicação interpessoal, a leitura de notícias ou o acesso a arquivos de áudio e vídeo). Por outro lado, para os leitores, tem-se um incremento quantitativo da atividade leitora paralela a uma maior fragmentação da leitura, atravessada de forma intermitente pela execução de outras atividades simultâneas (ler enquanto ouve música, por exemplo, como relata Tereza, ou manter-se disponível para verificar notícias e responder postagens eletrônicas, como Sérgio). Esta fragmentação e consequente redução da concentração prolongada à leitura é estimulada pela responsibilidade do livro em tela. As mídias digitais compelem o leitor a externar suas opiniões e comunicar suas realizações, incluindo aquelas relacionadas à leitura. Com isso, também concorrem para fragilizar o vínculo estabelecido entre o leitor e o livro em tela, reificando a experiência de leitura - logo imiscuída na comunicação da leitura realizada, que em princípio faria parte da experiência mesma. Os fins - a leitura concluída e, principalmente, a comunicação desta leitura - tornam-se prioritários, concorrendo para uma leitura eficiente, de ritmo acentuado e avaliada em função do cumprimento de certos requisitos básicos a atender (como a capacidade de descrever elementos da obra, por exemplo). A mensuração quantitativa da evolução desta tarefa, por sua vez - facultada pelo dispositivo -, contribui para a padronização da leitura e para a avaliação de sua eficiência.

A disposição em rede do livro digital contribui para que não apenas internamente ao dispositivo, mas internamente ao próprio texto, surjam estímulos - como hyperlinks - que capturam a distração do leitor, dificultando uma leitura continuada da obra. Esta "captura" dos momentos de distração ao longo da leitura faz com que a divagação, necessária para que se possa alcançar uma experiência mais rica com o texto, perca-se em meio ao labirintos das teias de informação, deslocando-se para fora da obra. Neste quadro, as leituras realizadas pelos leitores podem ser descritas menos como "distraídas" e "fluídas" (como se daria no caso do livro em papel), e mais como flutuantes e frenéticas.

Combinadas, a bidimensionalidade e a inconstância do fundo contribuem para que a "leitura fluída", associada aos livros tradicionais, dê lugar a um deslizar pela obra que não obedece mais à linearidade do texto e seus padrões de diagramação, mas que busca pontos para ancoragem de uma atenção superficial, eventualmente multifocada: uma leitura flutuante. Esta é a principal diferença que justifica a passagem de uma leitura fluída para uma leitura flutuante: o movimento autônomo do leitor em sua experiência de leitura é não apenas parcial e superficial, mas mais 
curto, de alcance restrito. O que significa, no limite, que as possibilidades dadas à imersão em uma obra mais complexa, que exige acompanhar o entrelaçamento de argumentos mais longos, é dificultada no livro em tela. Daí, em parte, a opção de Sérgio por realizar suas leituras de estudo sempre no livro em papel.

Ao contrário da placidez que o adjetivo "flutuante" pode sugerir, o ritmo desta busca é veloz, ansioso e intermitente. Por isso, engendra uma leitura frenética, que tende a promover uma experiência de leitura bastante diferente daquela contemplativa, característica dos primórdios da literatura impressa. Acirra-se, ao invés disso, a "fome de ler" típica da segunda revolução da leitura (Cavallo, \& Chartier, 1998). O tempo da leitura é afetado. Diferentemente do que acontecera por ocasião da pesquisa com leitores de livros tradicionais, todos os leitores de agora cumpriram rigorosamente os prazos auto-estipulados para sua leitura, por vezes mesmo adiantando-se a eles. O livro em tela parece ter deixado de constituir um locus de relaxamento, de distensão. Tornou-se, ao invés disso, medium para a execução de tarefas, as quais exigem disposição e uma postura alerta. $\mathrm{O}$ ambiente exterior por excelência de leitura do livro em tela não é mais aquele da confortável poltrona em silêncio, num canto isolado da casa ou da biblioteca - como ilustram os quadros românticos com personagens leitores. Tornou-se, ao invés disso, medium para a execução de tarefas que exigem disposição e postura alerta. A solidão e silêncio tornaram-se fatores contingentes. Este novo aspecto, dentre outras coisas, faz com que a leitura do livro em tela não provoque mais tanto prazer por si mesma, senão como tarefa meio. Laís é explícita em afirmar que a leitura no computador é associada a uma atividade de trabalho e menos prazerosa que a leitura em papel, mesmo quando o notebook é levado para a cama, onde supostamente encontraria ambiente adequado para uma atividade de lazer.

A percepção do livro em tela como objeto, assim como da estrutura da obra serão afetadas pela conjugação entre bidimensionalidade e inflexibilidade do livro em tela. As características espaciais do livro em tela dificultam a propriocepção do leitor e sua movimentação intuitiva pelo interior da obra. Isto faz com que o leitor não consiga conduzir sua leitura de um modo tão coerente com suas necessidades, ritmo pessoal e, principalmente, pelas exigências do texto, como ocorria ao ler um livro tradicional. $\mathrm{O}$ fato de o livro em tela impor certos modos de ler colabora para tornar o leitor menos autônomo e capaz de atender às exigências de leitura colocadas pela obra literária. Uma leitura flutuante e frenética comporta, como se pode depreender daí, uma experiência de ler livros diversa.

Relações do leitor com a estrutura da obra

A leitura flutuante assinala, no âmbito da experiência, a acentuação de uma tendência corrente desde o início do século XX de uma espécie de "estética das superfícies”, descrita por Siegfried Kracauer (2009). Ocupado com a experiência que se configurava quando da ascensão do cinema - marcada pela ilusão de movimento promovida pela sucessão de imagens montadas sobre a tela branca-, Kracauer mostra como a adesão do cinema e da fotografia à superfície externa do mundo relaciona-se tanto ao culto das aparências e do esplendor em curso na história da cultura, como ao frenesi do homem das cidades. Homem viciado em distração e que evita a reflexão, a fim de não "cair no vazio". Por um lado, este homem busca conferir um sentido aos fragmentos de imagens agrupadas como em um caleidoscópio; por outro, ele adere aos modelos fornecidos pelas obras de entretenimento, capazes de incutir-lhe como sonho as promessas ideológicas das classes dominantes aos subalternos. Uma estética das superfícies é coerente com a percepção dos objetos em tela (guardadas as devidas diferenças entre a imagem fílmica e a imagem em pixels do dispositivo digital). Para a leitura do livro, isto significa uma dificuldade de perceber a obra enquanto unidade forma-conteúdo [Gehalt], em razão do trânsito difícil do leitor pelos diversos níveis da obra. Privilegiando aspectos superficiais e fragmentados de seus elementos como "imagem-informação", o leitor apreende a obra de maneira parcial, encontrando modos específicos de ler na focalização de seus diversos segmentos. Uma vez eleito o elemento a ser tomado em perspectiva, o leitor desliza pelo texto, desobedece à sequência linear de frases, palavras e parágrafos e detêm-se nas passagens que chamam sua atenção ou colaboram para os propósitos contingentes daquela leitura específica. A ordem vertical do texto rolado de cima para baixo não se dá em sentido único, mas em movimentos curtos de vai-e-vem. O leitor centraliza sua leitura em si mesmo, dessacralizando a obra e colocando-a a serviço de suas impressões.

Como extremo desta tendência, tem-se a leitura de Amanda, que localiza prontamente as imagens de ação no texto, ancorando nestas a sua recepção. As repetidas leituras que ela realiza do mesmo texto promovem 
a satisfação do jogo continuado. Além disso, as repetições preenchem as lacunas de informação deixadas nos rápidos e ansiosos contatos anteriores com a obra. A cada nova leitura, Amanda descobre uma informação nova, sobre algum personagem ou passagem do enredo que não tinha merecido sua atenção durante as leituras anteriores do livro. As leituras de Laís e Sérgio, por sua vez, concentraram-se, respectivamente, nas formas do texto e nos conteúdos do livro. Sob esta perspectiva, Laís descreve em detalhe a diagramação e as ilustrações do livro, enquanto o relato de Sérgio concentra-se nas ideias em debate. Como exceção que confirma a regra, a leitura de Tereza mostrou-se mais obediente ao texto de caráter religioso, em virtude da sua necessidade de apreender os conteúdos morais da obra, ressaltados em detrimento de seus aspectos formais; ao mesmo tempo, porém, tais conteúdos são apreendidos por meio da descrição imagética dos ambientes e situações em destaque no texto, reforçadas pela versão cinematográfica do livro (cuja versão ela já assistira), que compareciam em sua leitura como ilustração dos preceitos e conteúdos aos quais elas serviam.

A leitura flutuante, neste contexto, corresponde não apenas a um movimento regular do olhar do leitor pela superfície da tela e irregular em relação à obra, mas também a uma leitura mais veloz do texto. Tem-se uma leitura ocasionalmente preocupada com a obra como um todo, mas não enquanto um conjunto integrado em uma análise coerente. Isto significa que o ritmo acentuado de uma leitura eficiente não torna a leitura realizada mais produtiva, tanto no que tange à possibilidade de oferecer ocasião para a experiência de leitura, quanto em se tomando como critério os objetivos da tarefa estipuladas pelo próprio leitor. Talvez em virtude da rapidez mesma com a qual concluem a atividade, os leitores (Sérgio, em particular, foi enfático nesta afirmação) mostravam-se dispostos a ler maior quantidade de livros em meios digitais do que no papel. Interessante assinalar, por outro lado, a grande quantidade de leitores inicialmente participantes deste estudo $(60 \%)$ que se negaram a participar da segunda parte da pesquisa porque não tinham lido livro nenhum (coisa que não ocorreu em pesquisa com livros tradicionais, que contou com $100 \%$ de adesão dos leitores para a segunda fase). Para além dos fatores mencionados que concorrem para esta não leitura, supomos, no caso específico destes leitores, que tal desistência decorra de três fatores: em parte, de uma resistência interposta quando os leitores deparam-se com uma chave de experiência diversa daquela já habitual e apreciada como leitura (que pareceu particularmente evidente nos casos de Heitor e Adélia); isto ao mesmo tempo em que, paradoxalmente, eles cedem mais facilmente à concorrência das demais funcionalidades disponíveis em seus aparelhos (como Catarina); elemento este que se soma às condições que cercam o declínio da leitura de livros de um modo geral.

A relação do leitor com a obra é afetada ainda por uma maior padronização do livro em tela em relação ao livro tradicional. A linguagem escrita (e a conservação, mesmo que temporária, à qual ela é associada) impede a realização de uma ubiquidade estrita das obras literárias, principalmente quando se trata de textos mais longos, que exigem mais tempo para sua leitura (uma atividade, por conseguinte, mais individualizada, realizada em um tempo e ritmo próprios). No entanto, quando a Internet oferece acesso global e imediato a determinados títulos, percebe-se um aumento na difusão de livros mais afeitos a uma padronização linguística e da própria experiência. Cresce, assim, a veiculação de livros em inglês e de uma literatura estruturalmente comercial. De modo cíclico, modifica-se tanto a oferta de títulos disponíveis no mercado editorial digital quanto a expectativa do leitor em relação às obras veiculadas, denotando um maior entrelaçamento das diversas modalidades de experiência estética à mídia digital, mais próximas do "ver" do que do "ler".

Funções da leitura e processos subjetivos

Cada um dos leitores possuía um projeto próprio para sua leitura, que exercia influência sobre a forma como se aproximavam da obra escolhida.

Sérgio foi o único a escolher o livro que leu antes de agendar o segundo encontro, valendo-se de uma leitura já programada. As demais leitoras, mesmo nutrindo motivos secundários, escolheram ler um título específico para a pesquisa. O livro de Sérgio seria usado para escrever um artigo sobre cultura e crítica musical. Amanda optou pela releitura de um livro de fantasia em inglês, parte de uma série publicada por sua escritora favorita. Fã do gênero, ela lê como entretenimento e sempre que possível, na espera entre atividades, por exemplo. Laís escolheu seu livro com cuidado, pensando no potencial da obra para avaliar as diferenças entre livros tradicionais e digitais: uma obra clássica, publicada por uma boa editora e com 
esmeradas ilustrações. Trabalhando na área editorial, Laís lê como técnica, interessada na forma como o texto aparece disposto no livro em tela. Tereza optou por um livro espírita que há muito queria ler; já tinha visto o filme baseado na obra, mas ainda não encontrara ocasião para ler o livro.

Os diferentes interesses de cada leitor, atravessados por seu lugar social e atribuindo funções diversas às suas leituras, conduzem sua atenção a diferentes partes da obra. Se a leitura do livro em tela tende a um nível de flutuação semelhante para os leitores, por outro lado, a atenção a diferentes elementos irá corresponder, em seu conjunto final, a modos de leitura distintos, conforme o objeto que o leitor tenha em perspectiva.

A leitura de Laís é uma leitura focada nos signos - diagramação, ilustrações e imagens descritas pela obra -, qualificando uma leitura formalista. Embora inicialmente a atenção de Laís não parecesse estar voltada para os aspectos estruturais da obra, a atenção ao texto como imagem e suas ilustrações a aproximava também das formas que estruturam a narrativa. Laís revela então um modelo de apreensão particular, apontando as divisões do texto e sua temporalidade, mas também o tamanho das passagens em cada uma das partes da obra em relação com seus conteúdos e formas linguísticas diversas. O modo de ler de Tereza configura uma leitura hermenêutica, atenta ao significado das palavras e frases, em busca de exemplos morais e lições de vida temporalmente invariantes. A leitura de Sérgio é uma leitura majoritariamente focada nos conteúdos do texto, uma leitura conteudística. À diferença da leitura hermenêutica empreendida por Tereza, porém, Sérgio busca estabelecer relações entre conteúdos e aspectos históricos da obra, buscando exercer seu poder de crítica mesmo que de forma pontual. Esta modalidade de leitura, necessário ressaltar, não deve ser atribuída ao caráter teórico do texto, uma vez que as obras teóricas não prescindem igualmente de sua forma. O modo de ler de Amanda, por fim, é aquele concentrado nas imagens que descrevem os episódios de ação narrados. Ela não se interessa pelas descrições dos ambientes ou aspectos interiores dos personagens - trechos que ela "salta" sempre que possível -, tampouco em uma apreciação estética da obra. Os diferentes elementos que a compõem interessam apenas em chave positiva ou negativa, enquanto capazes de promover ou não uma leitura agradável: antes de ler, ela avalia personagens, linguagem, trama e final do livro, a fim de julgar se terá uma leitura prazerosa ou se ler será "perda de tempo". Iniciada a leitura, tais elementos deixam de merecer maior atenção. A leitura imagética de Amanda, assim, não resulta da contemplação, mas da apropriação de modelos por identificação subjetiva. A percepção destes modelos e imagens aproxima-se, nesse sentido, daquela provada em outras mídias visuais da qual faz uso, como o cinema ou vídeo em streaming.

É possível avançar no estudo destas leituras, buscando compreender também como esquemas fornecidos pela obra são apropriados e/ou reconstruídos pelos leitores, em articulação com suas crenças ou necessidades psicológicas.

No caso de Sérgio, seus objetivos de leitura ancorados fora da obra conferem de algum modo unidade à obra lida, embora, ao final, sua leitura se revele parcial, talhada em função estrita dos objetivos previamente estipulados. A crítica histórica e conceitual faz-se de algum modo presente. Declarando-se um não especialista no assunto do livro, Sérgio compara a qualidade de seu olhar como leitor com aquele de um astrônomo amador, isto é, de alguém que observa e admira o objeto estudado sem dispor de técnicas que o permitam alcançar uma compreensão mais plena da obra. No caso de Tereza, o propósito religioso de sua leitura a faz buscar na obra exemplos e ensinamentos que justifiquem problemas sociais, políticos e pessoais (imbuídos de um significado espiritual). $\mathrm{O}$ livro fornece então um quadro que ultrapassa os limites temporais e espaciais de sua própria existência e a ajuda tanto a encontrar explicações para as mazelas do presente, quanto guia para suas escolhas.

No caso de Amanda, a leitura de entretenimento e o caráter antirreflexivo que ela the confere ensejam, em seu relato, uma longa digressão sobre a satisfação em identificar-se com os personagens protagonistas lindos, fortes, loiros e apaixonados, como ela mesma os descreve -, capazes de, a despeito de seus traumas e dramas pessoais, exercer uma liderança na história e vencer os seus inimigos: “quem nunca...", ela suspira. Ao afirmar explicitamente não gostar "de drama”, ela evita provar sentimentos angustiantes, afastando-se de qualquer realismo literário. Ela reconhece que os elementos fantásticos do livro resumem-se às características dos personagens não humanos, uma vez que tanto o cenário (Nova Iorque, no caso) quanto os elementos dramáticos da narrativa são bastante estereotipados. O sucesso dos protagonistas funcionam então como inspiração para que ela mesma consiga superar 
as vicissitudes cotidianas (das quais "ninguém gosta de se ocupar") e seguir adiante. É como se ela pretendesse esvaziar-se de si mesma. A "fuga" que esta leitura promove não opera como aprendizado ou experiência, de algum modo pertinente às reflexões da leitora, mas como simples negação do sofrimento. No caso de Laís, sua leitura formalista acaba impelindo-a a um certo presentismo, que evidencia o estranhamento produzido por narrativas datadas em um tempo passado. Por outro lado, Laís acaba se configurando como a única leitora dedicada à realização de uma experiência estética propriamente dita. Fazendo um parêntesis para o frequente recurso da leitora aos comentários críticos que abrem o livro, que não a impede de exercitar suas próprias reflexões sobre o texto.

Chama a atenção que, embora os leitores estivessem voluntariamente dispostos a participar da pesquisa, eles precisassem atribuir uma função externa à sua leitura, como se a atividade em si já não fosse mais suficiente para justificar o tempo devotado ao texto. É a experiência estética realizada por Laís, contudo, que torna possível a ela relacionar as formas e imagens do texto às quais devota sua leitura com os conteúdos da obra, inaugurando um diálogo que a permite compreender melhor a narrativa, analisar seus aspectos históricos e filosóficos e também deliciar-se com suas passagens - como parece evidente nos momentos em que ela reconta algumas das peripécias e inacreditáveis aventuras do protagonista. Embora esta experiência de leitura pareça guardar algumas diferenças em relação àquela possível no livro em papel, não se pode afirmar que Laís não realizou uma experiência de leitura. Do mesmo modo, apesar de Tereza não pretender a realização de uma experiência estética propriamente dita, sua leitura parece ter tido sobre si o efeito de um aprendizado, nutrindo transformações pessoais. Sua leitura, contudo, mostrou-se incapaz de resultar em um diálogo crítico com a obra.

É possível dizer que os leitores evitaram empreender uma imersão na obra durante suas leituras, exceção feita à leitura de Laís e, em parte, aquela de Sérgio. No caso de Amanda e Tereza, ocorre um contato mais próximo com a obra, configurando porém uma leitura que não ameaça ou desafia, engendrada em um ambiente já conhecido e seguro para as leitoras. Mais centrados em si mesmos, os quatro leitores mostraram-se pouco abertos e disponíveis para uma experiência nova. Ao contrário, planejaram a atividade de leitura de modo a otimizar seu tempo, com vistas à tarefa pré-estabele- cida. O leitor de livros na tela apresenta-se, de forma mais evidente do que em outros suportes, como um leitor utilitarista e receoso. Daí a adesão a modelos já avaliados de leitura, o recorte de fragmentos e a dificuldade da análise. No meio do caminho entre a experiência pessoal e a crítica, para retomar um tema caro à filosofia de Kracauer, o leitor não avança nem bem para um lado, nem para o outro, já que a experiência é condição para a crítica, e vice-versa.

\section{Considerações finais: mudanças estruturais na leitura}

Neste artigo, destacaram-se, como modos característicos de ler livros em meios digitais, a leitura flutuante, a leitura frenética e a leitura eficiente. Sob estas modalidades de leitura, o texto literário é percebido em seus aspectos superficiais, de forma veloz e não linear. O leitor busca, neste procedimento, por imagens e informações de interesse, nas quais eventualmente se deter. Esta "leitura administrada" revela um leitor utilitarista e receoso de aventurar-se em experiências de leitura novas, despendendo tempo com resultados incertos. Ancorando sua leitura em elementos parciais do texto, o leitor simplifica a tarefa de ler organizando sua "flutuação" pela superfície da tela. Este procedimento deu ensejo a quatro tipos de leitura, de acordo com o "objeto de ancoragem" escolhido pelo leitor: a leitura formalista; a leitura conteudística; a leitura hermenêutica; e a leitura imagética.

Não é demais ressaltar que não constituía objetivo do estudo aferir as capacidades individuais dos leitores. As tendências apontadas configuram-se a partir de categorias próprias ao livro em tela e da leitura mediada por este, as quais participam de e $n a$ estruturação de novas formas da experiência na era digital, esperando que este estudo possa oferecer ao indivíduo instrumentos capazes de nutrir, em alguma medida, sua autonomia como leitor. Enfatiza-se, neste sentido, os aspectos culturais e históricos da presente investigação, esperando que em um futuro próximo seja possível realizar novos estudos e avaliar as consequências do fenômeno em curso. Por ora, convém ressaltar que não se pretende com esta pesquisa esgotar o tema da leitura de livros digitalmente mediada, mas sim oferecer ocasião para uma análise dos fenômenos envolvendo a mediação da experiência na era digital, bem como de suas implicações para a leitura e para a formação cultural do indivíduo. 
Possivelmente, uma amostra de leitores mais ampla, e mesmo a leitura de títulos diferentes, expusesse mais tipos de leituras e de leitores. Acredito, contudo, ter atingido os objetivos postos à pesquisa ao identificar as tendências que marcam os modos de ler livros em meio às transformações provocadas pela digitalização da cultura. Como vimos, as características do livro digitalmente mediado contribuem para sedimentar seus usos e modos de ler. O tempo e a solidão que um certo tipo de leitura requer modificam-se quando o objeto mediador não promete mais ao leitor um afastamento do mundo ao redor - como ocorria com o livro em papel -, e uma imersão na obra, mas antes uma imersão na corrente de conexões que os aparelhos digitais disponibilizam. Tanto o livro em tela - devido às características do dispositivo como do texto em si - quanto a experiência do leitor concorrem para a distração durante a leitura. No entanto, esta distração não atende às finalidades da própria leitura, mas serve de mote para que o leitor explore novas informações em rede. Se é verdade que a leitura de um uma obra literária na tela de um celular promove maior acesso e portabilidade do livro, isto não significa que o leitor irá conseguir ler melhor por conseguir acessar o texto ubiquamente disponível por meio de seu smartphone. Nesse sentido, a leitura em tela parece oferecer mais riscos de repetição do mesmo do que possibilidades de crítica, criação, ruptura e/ou novos aprendizados ao leitor que se aventure por seus meandros. Aquela articulação imaginada por Benjamin entre experiência, imagem e memória reduz-se significativamente neste horizonte. Neste novo ambiente, não por acaso liso e envidraçado, os momentos de distração do leitor em relação ao texto assumem formas e funções pré-determinadas, cristalizando modos de leitura específicos e encolhendo a experiência estética possível.

\section{Referências}

Adorno, T. W. (2009). Dialética Negativa (M. A. Casanova, trad.). Rio de Janeiro, RJ: Zahar.

Adorno, T. W. (2010). Teoria da semiformação. In Pucci, B., Zuin, A. S., \& Lastória, L. A. (Orgs.), Teoria crítica e inconformismo (pp. 7-40). Campinas, SP: Autores Associados.

Benjamin, W. (2015). Baudelaire e a modernidade (J. Barrento, ed. e trad.). Belo Horizonte, MG: Autêntica.

Cajochen, C., Frey, S., Anders, D., Späti, J., Bues, M., Pross, A. et al. (2011). Evening exposure to a light-emitting diodes (LED)-backlit computer screen affects circadian physiology and cognitive performance. Journal of Applied Physiology, 110(5), 1432-1438. https://doi.org/10.1152/japplphysiol.00165.2011

Cândido, A. (1999). Crítica impressionista. Remate de Males, (Antonio Candido): 59-62.

Cavallo, G., \& Chartier, R. (1998). História da leitura no mundo ocidental. São Paulo, SP: Ática.

Dadico, L. (2012). A “fisiognomia” do livro no estudo psicológico da leitura. Psicologia em Estudo, 17(4), 629-638.

Instituto Pró-Livro. (2016). Retratos da leitura no Brasil (4a ed). São Paulo, SP: Instituto Pró-Livro.

Kracauer, S. (2009). O ornamento da massa (C. E. J. Machado, \& M. Holzhausen, trads.). São Paulo, SP: Cosac Naify.

Mangen, A., Walgermos, B. R., \& Brønnick, K. (2013). Reading linear texts on paper versus computer screen: Effects on Reading comprehension. International Journal of Educational Research, 58, 61-68. https://doi.org/10.1016/j.ijer.2012.12.002

Noyes, J. M., \& Garland, K. J. (2014). Computer - vs. paper-based tasks: are they equivalent? Ergonomics, 51(9), 1352-1375. https://doi.org/10.1080/00140130802170387

\section{Luciana Dadico}

Doutorado em Psicologia pelo Instituto de Psicologia da Universidade de São Paulo (IP-USP). Pesquisa de pósdoutorado junto ao IP-USP, com financiamento da Fundação de Amparo à Pesquisa do Estado de São Paulo (Fapesp). E-mail: ludadico@usp.br 
Endereço para envio de correspondência:

Instituto de Psicologia da Universidade de São Paulo

Avenida Professor Mello de Morais, 1721 - Butantã. CEP: 05508-030.

São Paulo , SP, Brasil.

Recebido 22/12/2016

Aprovado 17/07/2017

Received 12/22/2015

Approved 07/17/2017

Recebido 22/12/2016

Aceptado 17/07/2017

Como citar: Dadico, L. (2017). Modos de ler livros em meios digitais: transformações da experiência. Psicologia: Ciência e Profissão, 37(3), 725-737. https://doi.org/10.1590/1982-3703004662016

How to cite: Dadico, L. (2017). Ways of reading books in digital media: transformations of experience. Psicologia: Ciência e Profissão, 37(3), 725-737. https://doi.org/10.1590/1982-3703004662016

Cómo citar: Dadico, L. (2017). Modos de leer libros en medios digitales: transformaciones de la experiencia. Psicologia: Ciência e Profissão, 37(3), 725-737. https://doi.org/10.1590/1982-3703004662016 